\title{
IMPLANTAÇÃO DE PROCEDIMENTO OPERACIONAL PADRÃO EM UMA LAVANDERIA INDUSTRIAL
}

\section{DEPLOYMENT OF OPERATIONAL STANDARD PROCEDURES IN THE INDUSTRIAL LAUNDROMAT}

Vinicius Aguiar de Campos'; Aline Marques Fernandes dos Santos'; Gabriela Oliveira Fonseca'; Andréia de Menezes Olivo².

${ }^{1}$ Universidade do Oeste Paulista - . UNOESTE, Curso de Engenharia de Produção, Presidente Prudente - SP. e-mail: vini aguiar @ hotmail.com

RESUMO - A busca por um modelo de padronização e sistematização das tarefas que compõem as etapas de produção de uma lavanderia industrial se faz imprescindível para a busca de um lugar no mercado diante da grande concorrência. Com o intuito de melhorar a qualidade, tempo de produção e índice de satisfação dos clientes, implantou-se a padronização por meio de gerenciamento de rotina e de processos do nível operacional. Para isto foi realizado uma pesquisa exploratória, descritiva e analítica do processo de produção, o que resultou na implantação do programa $5 \mathrm{~S}$ que visou qualidade no ambiente organizacional e auxiliou no processo de implantação do programa de procedimentos operacionais padrão (POP), onde foram utilizados conceitos de Lead Time, set-up, ciclo PDCA. Estes programas otimizaram a produtividade e proporcionou adequação nos prazos de entrega e melhor controle da qualidade do serviço prestado ao cliente. Palavras-chave: padronização; lavanderia industrial; procedimentos operacionais.

ABSTRACT - The search for a model of standardization and systematization of tasks that comprise the steps of producing an industrial laundry is indispensable to the pursuit of a place in the market the big competition. In order to improve the quality, production time and satisfaction of customers, was implanted the standardization through routine management processes and operational level. For this exploratory, descriptive and analytical study of the production process, which resulted in the implementation of the $5 S$ program that aimed at quality organizational environment and assisted in the process of implementation of standard operating procedures (POP), where concepts of Lead Time, set-up, PDCA cicle. These programs optimized gave us adequate delivery and better control of the quality of provided customer service.

Keywords: standardization; industrial laundromat; Operational procedures. 


\section{INTRODUÇÃO}

Estabelecimentos como hotéis, hospitais e restaurantes estão procurando se dedicar cada vez mais à sua atividade principal, preocupados com a produtividade, busca-se um processo que mantenha um padrão eficaz e permanente de qualidade, buscando assim a terceirização do setor de lavanderia para diminuir custos e trabalhos, deixando as responsabilidades desse setor para outra empresa. Por conta desses motivos, é notório o aumento de lavanderias que prestam este serviço.

Segundo a Agência Estado (2011), no Brasil existem cerca de nove mil lavanderias e este setor emprega aproximadamente 300 mil funcionários. Neste cenário de grande concorrência é essencial que as lavanderias apresentem um diferencial em seus serviços e o principal meio de alcançar a liderança do mercado é fornecer um serviço de alto nível de qualidade.

A Qualidade se fixa na excelência do produto, foca nas ferramentas da área para satisfazer o cliente e ter controle estatístico das atividades geradoras dos produtos. Um produto ou serviço de qualidade é aquele que atende perfeitamente, de forma confiável, acessível, segura e no tempo certo às necessidades do cliente (NEVES, 2007).

Para estabelecer um padrão de qualidade e facilitar a negociação junto aos clientes, foi desenvolvida pelo Sindicato Intermunicipal de Lavanderias no Estado de São Paulo (SINDILAV) em parceria com ANEL, uma ferramenta para garantir a evolução das empresas e melhoria no desempenho.

A lavanderia deve se enquadrar aos padrões cada vez mais rígidos de legislação estruturados em um Sistema de Gestão chamados SQS. Este programa é baseado nas normas da International Organization for Standardization (ISO), certificando os aprovados em três níveis: bronze, prata e ouro. Estes programas têm como objetivo melhorar o desempenho dos serviços prestados, reduzindo custos de itens críticos e provendo controle contínuo sobre a conformidade em relação à legislação, visando à obtenção de um processo padrão de qualidade (SINDLAV, 2014).

De acordo com Guimarães (2011), as empresas são constituídas de processos dos quais o controle de qualidade deve ser feito em cada um deles para assegurar a satisfação do cliente. Ou seja, para alcançar a qualidade final de um produto é preciso que todo o processo seja controlado.

Uma forma de controlar cada etapa do processo é através da padronização. A padronização é uma técnica que visa reduzir a variabilidade dos processos de trabalho sem prejudicar sua flexibilidade (FONSECA, 2014). 
O presente trabalho tem como objetivo propor um modelo de padronização e sistematização das tarefas que compõem as etapas de produção de uma lavanderia industrial, por meio da formulação de um programa de procedimentos operacionais padrão (POP's) embasado na prática do programa $5 \mathrm{~S}$ e ciclo PDCA, buscando o aumento da qualidade nos no serviço prestado.

\section{FUNDAMENTAÇÃO TEÓRICA}

Esta seção apresenta os conceitos e métodos que dão suporte ao desenvolvimento deste trabalho: A padronização com criação de Procedimento Operacional Padrão (POP), a ferramenta $5 \mathrm{~S}$ e o ciclo de melhoria contínua (PDCA).

\subsection{PADRONIZAÇÃO}

A padronização de processos é uma forma eficaz de se organizar e gerenciar a maneira como as atividades da empresa agregam valor. Entre seus benefícios estão: a utilização adequada dos equipamentos, matérias-primas e mão de obra; auxilio no treinamento operacional; aumento da produtividade e a melhoria da qualidade de produtos e serviços; controle de produtos e processos, além da segurança do pessoal e dos equipamentos (GUIMARÃES, 2011).

Quando já estabelecidos os procedimentos necessários e garantida sua qualidade, o Procedimento Operacional Padrão (POP) pode ser utilizado como forma de assegurar uma padronização no ciclo produtivo. O POP é um dos ferramentais que permitem que as tarefas sejam realizadas sempre da mesma forma e fornecem instruções detalhadas de todas as etapas e métodos participantes do processo de fabricação do produto ou atendimento. Toda essa padronização garante que determinada função possa ser realizada sempre da mesma forma, o que auxilia o processo de controle de qualidade.

Os POP's devem existir nas empresas e contemplar todas as etapas produtivas, atividades prévias e posteriores de modo que seja possível planejar adequadamente o que se pretende fazer e se consiga, na sequência, executar esse planejamento de forma correta. Tudo isso se desdobra em inúmeros procedimentos específicos, adaptados à cada empresa e bem elaborados, no sentido de ser um instrumento benéfico às atividades cotidianas (PINEZE, CONSONI, MARQUES; 2014).

\section{$2.25 S$}

Outra ferramenta utilizada para melhoria do processo é o $5 S$, conforme Marshall et al. relata. Essa ferramenta é dividida em cinco sensos: Seiri (utilização); Seiton (ordenação); Seisou (limpeza); Seiketsu (saúde) e Shitsuke (autodisciplina). 
Canto, Santos \& Gohr (2006), detalham o significado de cada ação desses cinco sensos de qualidade empregados.

Seiri (utilização) - O primeiro senso do $5 S$ visa identificar materiais, equipamentos, ferramentas e informações, onde é definido o grau de necessidade dos mesmos e descartado os itens desnecessários ou dando outro destino a estes;

Seiton (ordenação) - No segundo senso a organização deve identificar a necessidade de alocação de cada item, padronizando o seu uso e local adequado para guardar no intuito que todos sigam o procedimento, devolvendo o objeto no mesmo local encontrado anteriormente. Cada coisa deve ter o seu devido lugar.

Seiso (limpeza) - Realizar a limpeza, identificando os pontos de sujeira e suas respectivas causas. Na execução do senso de limpeza deve-se realizar inspeção rigorosa no ambiente de trabalho, de forma a identificar futuros problemas que possam causar transtornos e acidentes. O mais importante nesse conceito não é o ato de limpar, mas sim o ato de "não sujar".

Seiketsu (saúde) - Também chamado senso de asseio, refere-se ao estado que se atinge coma prática dos três sensos anteriores, sendo acrescido de atividades rotineiras e habituais em termos dehigiene, segurança no trabalho e saúde pessoal.
Shitsuke (autodisciplina) - Está vinculada a manutenção do programa, onde é necessário desenvolver o senso de autodisciplina das pessoas para manter os níveis de organização e qualidade pessoal e ambiental, redução de acidentes e de desperdícios, melhoria do clima organizacional, entre outros. Este hábito é o resultado do exercício da força mental, moral e física.

O programa 5S, é considerado o passo inicial para a implantação de programas de qualidade, pois permite um ambiente organizado e saudável para todos os colaboradores da empresa. Além disso, proporciona resultados como redução de custos, agilidade e maior qualidade dos serviços prestados.

Para Staino, et al. (2013) o programa $5 S$ prepara o caminho para a introdução de programas de qualidade mais avançados. Por isso, antes de dar início ao mapeamento de processos, é necessário com o auxílio de cada senso, promover a disciplina através da consciência e responsabilidade de todos, de forma a tornar o ambiente de trabalho agradável, seguro e produtivo.

O 55 também visa aproveitar o potencial de cada colaborador reduzindo desperdícios de tempo, ordenando o ambiente de trabalho, realocando itens inutilizados no momento para futuro uso ou possível descarte (MARSHALL et al., 2006). 
Pode-se entender o fluxo seguido pela ferramenta $5 S$ através da imagem abaixo:

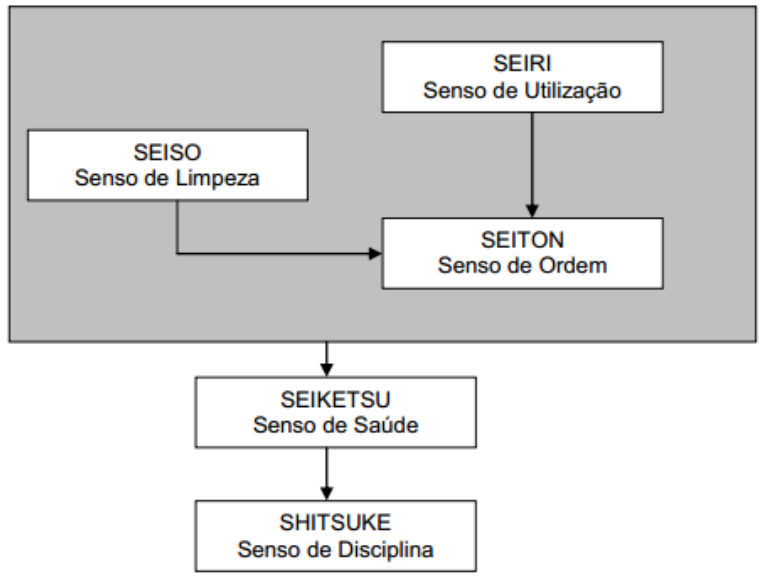

Figura 1. Fluxo do $5 \mathrm{~S}$

Fonte: Rodrigues, 2006

\subsection{PDCA}

A organização que deseja chegar aos seus objetivos necessita desenvolver um padrão que permita ações como o planejamento e o controle da padronização. Comumente, tal controle é feito através da metodologia PDCA, mostrado na figura a seguir.

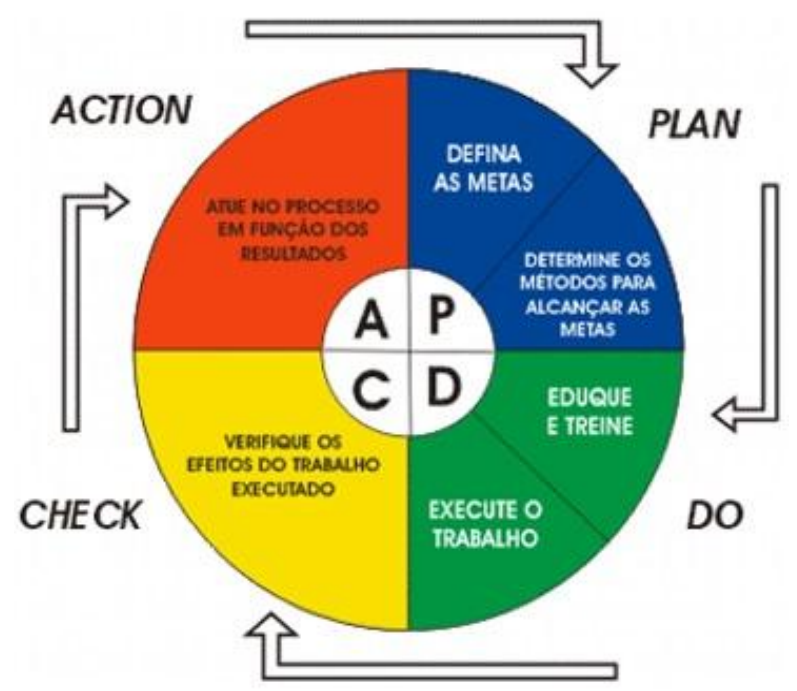

Figura 2. PDCA - Método de controle de processos

Fonte: Campos, 1996
Segundo Deming (1990), este método de controle é composto por quatro etapas, que produzem os resultados esperados de um processo. As etapas do PDCA são:

- Plan (Planejamento): consiste no estabelecimento da meta ou objetivo a ser alcançado, e do método (plano) para se atingir deste objetivo.

- Do (Execução): é o trabalho de explicação da meta e do plano, de forma que todos os envolvidos entendam e concordem com o que se está propondo ou foi decidido.

- Check (Verificação): Durante e após a execução, deve-se comparar os dados obtidos com a meta planejada, para se saber se está indo em direção certa ou se a meta foi atingida.

- Action (Ação): transformar o plano que deu certo na nova maneira de fazer as coisas.

O ciclo PDCA é uma ferramenta de qualidade rápida e eficaz na resolução de problemas. Para Neves (2007), esse ciclo padroniza as informações do controle da qualidade, evita erros lógicos nas análises, e torna as informações mais fáceis de entender. Além disso, o PDCA pode ser utilizado para a implantação de melhorias no processo de forma adequada.

É aplicado para melhorar continuamente os resultados do processo, visando o mercado, cada vez mais exigente. Neste caso, geralmente são usados valores, 
como metas; por exemplo, redução de custos, aumento da produtividade, etc. E a cada repetição do ciclo os planos se adequam aos objetivos da empresa.

\section{METODOLOGIA}

Antes da implantação do POP foi realizada a implantação do programa $5 \mathrm{~s}$, o método utilizado nesta pesquisa é o estudo de caso, o qual destina-se a avaliar uma área específica do conhecimento, neste caso, a aplicação de conceitos da qualidade e gestão de operações no setor de lavanderia industrial. De acordo com Yin (2001), um estudo de caso permite entender a realidade a ser estudada, sendo previamente planejado por meio da literatura, experiências e características próprias do caso.

São apresentadas as etapas planejadas para a implantação do Programa 5S:

Etapa 1 - Diagnóstico: Ao iniciar o estudo para a implantação dos programas propostos, foi realizado um diagnóstico nas áreas de produção, qualidade e ergonomia. Etapa 2 - Formação e capacitação da equipe: Foi formada uma equipe de auditoria composta por quatro colaboradores de diferentes setores mais os proprietários. Para integrá-los ao programa e entender sua importância se fez necessário fornecer treinamentos/capacitação aos colaboradores, a qual foi ministrada pela equipe de pesquisa. Etapa 3 - Planejamento do Programa 5S: Durante esta etapa foi elaborado um plano de ação, por meio do método $5 \mathrm{~W} 1 \mathrm{H}$. Este método utiliza questõeschave (O que (What), Quem(who), Quando(When), Onde (Where), Porque (Why) e Quanto (How)), para fornecer informações principais para que uma atividade seja executada (LIN; LUH, 2009). Etapa 4 - Implantação dos Sensos: A seguir, apresentam-se as atividades desenvolvidas nos sensos de descarte e organização. Senso de descarte: As atividades realizadas foram: definir a área de descarte, definir procedimentos e critérios para o descarte, levantamento dos itens descartados, providenciar destinos para descartados e registrá-los, afixar cartazes do programa $5 \mathrm{~S}$ e delegar funções para a equipe. O Senso de Organização: para este senso foi elaborado um roteiro detalhado dos procedimentos a serem cumpridos, materiais a serem comprados e funções da equipe de qualidade. Etapa 5 - Avaliação: As avaliações dos sensos de descarte e organização ocorreram mensalmente por meio de auditorias realizadas pela equipe da empresa.

A Tabela 1 demonstra as perguntas frequentes a serem utilizadas no processo de implantação do programa para os Cinco Sensos. 
Tabela 1. Perguntas frequentes na implementação do $5 S$

\begin{tabular}{|c|c|c|c|}
\hline Avaliação da Implementação dos 5 S & Local/Área: & Antes & Depois \\
\hline \multirow{3}{*}{ Seiri } & Todas as coisas desnecessárias foram removidas? & & \\
\hline & $\begin{array}{l}\text { Comedores, áreas de trabalho e posições específicas estão } \\
\text { claramente identificados? }\end{array}$ & & \\
\hline & Existe algum procedimento para remoção de itens desnecessários? & & \\
\hline \multirow{3}{*}{ Seiton } & Existe um lugar bem definido para cada coisa? & & \\
\hline & Todas as coisas estão em seu lugar? & & \\
\hline & As posições são óbvias e fáceis de identificar? & & \\
\hline \multirow{4}{*}{ Seiso } & $\begin{array}{l}\text { As áreas de trabalho, equipamentos, ferramentas e mesas estão } \\
\text { limpas e livres de restos de material? }\end{array}$ & & \\
\hline & Materiais de limpeza estão disponíveis e acessivos? & & \\
\hline & $\begin{array}{l}\text { As faixas de corredores, códigos de endereçamento estão bem } \\
\text { conservadas e visiveis? }\end{array}$ & & \\
\hline & $\begin{array}{l}\text { Existe uma programação para a realização de limpezas e há } \\
\text { divulgação da mesma? }\end{array}$ & & \\
\hline \multirow{4}{*}{ Seiketsu } & Todas as informações necessárias estão disponíveis? & & \\
\hline & Os painéis visuais estão atualizados? & & \\
\hline & Os padrões de 5 S estão definidos e claramente divulgados? & & \\
\hline & Há aderência aos padrốes vigentes? & & \\
\hline \multirow{3}{*}{ Shitsuke } & Os procedimentos de 5 S são cumpridos? & & \\
\hline & Existe uma auditoria corrente e um sistema de feedback para 5S? & & \\
\hline & Existe um sistema para responder à auditoria ou feedback? & & \\
\hline Nome do avaliador: & Pontuação total: & & \\
\hline
\end{tabular}

Fonte: Autoria própria

Depois de finalizada a etapa de implantação do 5S, deu-se início a implantação do programa de Procedimentos Operacionais Padrão na lavanderia.

$$
\text { A elaboração dos POP's }
$$
fundamentou-se basicamente em fazer o mapeamento de cada etapa do processo da lavanderia industrial, especificando suas particularidades, contemplando todos os passos para a realização das tarefas e analisando cada um desses passos a fim de verificar qual é a maneira mais eficiente de realização.

Para isso, foram realizadas visitas in loco objetivando analisar a realidade do local bem como a quantidade e tipo de equipamentos utilizados na produção e realização do processo, número de colaboradores, condições das instalações internas e externas, layout de funcionamento e realização das tarefas, acondicionamento dos materiais e produtos processados, bem como a logística de entrega dos produtos, utilização dos produtos químicos, acondicionamento e manipulação destes.

Cada uma das visitas na empresa foi acompanhada por funcionários responsáveis pela função observada e gestores para um melhor entendimento da rotina de produção, visto que estes participaram diretamente da 
confecção do POP sob consenso e aprovação das sugestões de melhoria.

Antes da implantação do POP os colaboradores e gerência receberam treinamento envolvendo Boas Práticas de Fabricação (BPF), conceitos sobre $5 \mathrm{~S}$ e entendimento do funcionamento do ciclo PDCA.

Após a elaboração completa do POP os gestores analisaram todos os itens verificando se estavam de acordo com a realidade da lavanderia, durante o período de uma semana foi monitorado o cumprimento dos procedimentos e preenchimento correto das planilhas, algumas falhas foram observadas na realização das tarefas e entendimento do preenchimento correto das planilhas por parte dos funcionários. Estas dificuldades foram expostas aos gestores que imediatamente realizaram as correções e planos de ação para prevenção destes desvios.

\section{PROCEDIMENTO OPERACIONAL PADRÃO}

A realização do treinamento operacional não é o suficiente para garantir que as atividades sejam executadas de uma maneira uniforme e padronizadas. Para atender a esta padronização, além do treinamento dos colaboradores, foi elaborado um manual de Procedimentos Operacionais Padrão, que objetivou descrever as etapas do processo e viabilizar a consulta pelos colaboradores responsáveis por cada tarefa, a fim de implantar a padronização de todas as atividades realizadas no setor de operações.

A dinâmica do manual foi organizada e sistematizada em oito procedimentos operacionais (POP's) para lavanderia industrial em estudo, possuindo uma breve apresentação da empresa, contendo: Nome Empresarial, Nome Fantasia, CNPJ, Inscrição Estadual, Endereço, Classificação e Foco de Atuação. Também incluso nessa apresentação estão os Serviços Oferecidos, Funções de cada cargo e o objetivo esperado pela empresa com a implantação do plano.

O detalhamento de cada etapa foi elaborado de forma padrão durante todo o plano, composto por um cabeçalho, com o objetivo de deixar de forma explícita o nome do POP (procedimento a qual se refere). Incluindo: Logomarca da Empresa, Nome da Empresa, Código do POP, Nome do Procedimento e a numeração da página do POP.

Após o cabeçalho, o detalhamento das etapas do processo, parte principal e fundamental do POP, foi montada por meio da observação e análise individual dos colaboradores em seu ambiente de trabalho. Este processo é formado pelas etapas:

(1) Recebimento: Essa etapa do processo tem como objetivo separar as 
toalhas recebidas e prepara-las para a lavagem. Os funcionários devem retirar as toalhas dos seus respectivos sacos para fazer a conferência do número de toalhas recebidas, anotar a quantidade e o nome do cliente na planilha de recebimento, e fazer a separação por tipo e cor, em uma área reservada.

2) Lavagem: Essa etapa do processo tem como objetivo lavar as toalhas para eliminação total de manchas e sujeiras. 0 tipo de lavagem depende de alguns fatores como a cor, material e nível da sujeira. Tudo deve ser levado em conta pelo operador da máquina para que o cálculo dos produtos colocados na lavadora possa ser o correto para aquela situação.

(3) Inspeção: Essa etapa do processo tem como objetivo realizar a inspeção das toalhas para verificação da eficiência da lavagem. Foi sugerida à empresa a criação dessa etapa, para que evite o caso onde toalhas mal lavadas e com manchas acabem sendo identificadas apenas ao final de todas as outras etapas.

(4) Centrifugação: Essa etapa do processo tem como objetivo centrifugar todas as toalhas que já foram lavadas e inspecionadas. O funcionário deve estimar o tempo necessário para que o excesso de água possa ser retirado das toalhas.

(5) Secagem: Essa etapa do processo tem como objetivo levar todas as toalhas que foram centrifugadas para a secadora. Cabe ao funcionário fazer a programação correta da temperatura de aquecimento e o tempo de duração da secagem.

(6) Esticamento/Separação: Essa etapa do processo tem como objetivo preparar para a dobra as toalhas que já passaram pelo processo de lavagem. Nesse momento foi sugerido à empresa adotar uma medida até então não realizada. Para otimizar o tempo do processo em geral, deve-se separar as toalhas de acordo com o cliente, ou seja, o funcionário deve analisar as prioridades de entrega e focar somente na dobra de todas as toalhas desse cliente.

(7) Dobragem: Essa etapa do processo tem como objetivo dobrar as toalhas e deixálas prontas para o empacotamento. funcionário deve dobrar as toalhas de acordo com o modelo sugerido, pois testes indicaram ser a forma mais rápida e eficiente.

(8) Conferência/Empacotamento: Essa etapa do processo tem como objetivo a conferência e o empacotamento dos montes de toalhas. Devem ser separados os montes corretos de toalhas para cada embalagem, juntamente com sua identificação.

Todas as etapas descritas estão ilustradas no manual de Procedimentos Operacionais Padrão (POP), este formato visou melhorar o entendimento e visualização do colaborador, de como realizar cada etapa de suas respectivas tarefas. 
A figura a seguir mostra cada etapa do processo produtivo que foi analisada para a implantação do Procedimento Operacional Padrão.

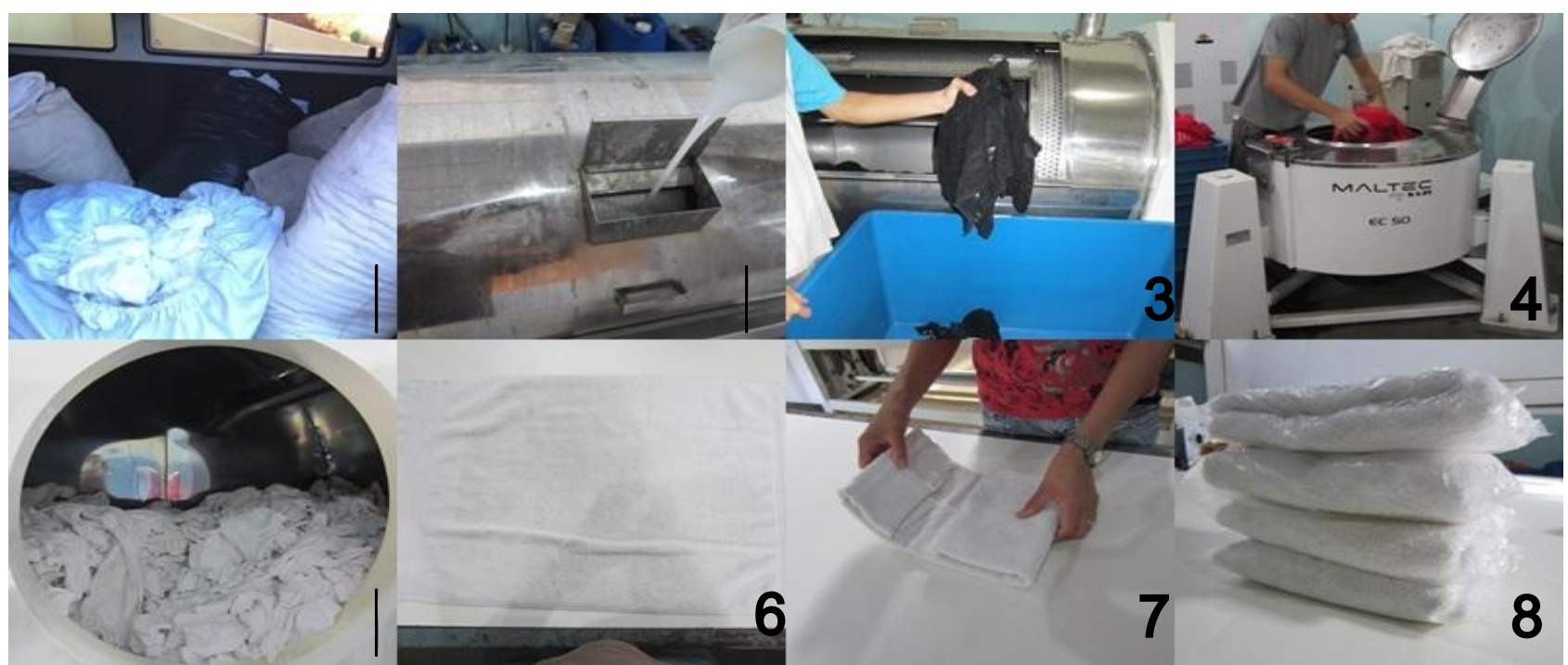

Figura 3. Etapas do processo descritas no manual de Procedimentos Operacionais Padrão (POP). Fonte: Autoria própria

\section{RESULTADOS}

A elaboração e a implantação do POP possibilitou aos colaboradores a compreensão de que fazer o controle e trabalhar de uma maneira sistematizada seria a única forma de otimizar o processo produtivo levando em consideração as melhores ações a serem tomadas em cada etapa, conquistando a confiança dos clientes, diminuindo o número de reclamações e reprocessos.

A utilização dos conceitos do $5 S$ foi fundamental para o bom funcionamento do POP's, pois teve o intuito de proporcionar um ambiente organizacional de qualidade, que auxiliou em deixar a empresa preparada para futuras aplicações das etapas do ciclo PDCA.

Para o programa 5S, a etapa de prévio levantamento de toda a estrutura operacional da empresa, permitiu a elaboração pela equipe de auditoria interna de treinamentos e reciclagem das práticas do programa e a elaboração de uma sequência de planilhas de verificação que serviram de base para implantação e acompanhamento.

Como resultados para a implantação do 5 S foi possível identificar na etapa 1 de Diagnóstico: a necessidade de implantação dos 5 Sensos a fim de melhorar a organização dos materiais, estrutura física e as informações. Além disso, preparar a empresa para introduzir outras ferramentas de qualidade e motivar seus colaboradores a se envolver com o dia-dia da empresa. Os principais itens identificados foram: melhorar a produtividade, reduzir o tempo de entrega dos produtos, ambiente desorganizado e sujo pouca comunicação entre os colaboradores e 
estrutura limitada fisicamente. A etapa 2 Formação e capacitação da equipe: A equipe de auditoria interna da empresa foi capacitada por meio de sensibilizações sobre qualidade e programa 5S, pela equipe de pesquisa. Que também foi responsável por acompanhar e implantar as fases do plano de ação. Durante a implantação dos sensos de descarte e organização ocorreram reuniões semanais para discutir novas ações. A etapa 3 de Planejamento do Programa 5S, foi elaborado um plano de ação $(5 \mathrm{~W} 1 \mathrm{H})$ para cada senso (descarte e organização). Os encontros de planejamento foram realizados semanalmente. A equipe de qualidade da empresa foi responsável por providenciar os materiais, implantar as ações e coletar os dados. Nesta etapa, também houve o registro fotográfico da situação atual da empresa, com o intuito de analisar os resultados após a implantação do programa, conforme mostra a imagem a seguir que retrata a mudança na forma de entrega dos materiais aos clientes:

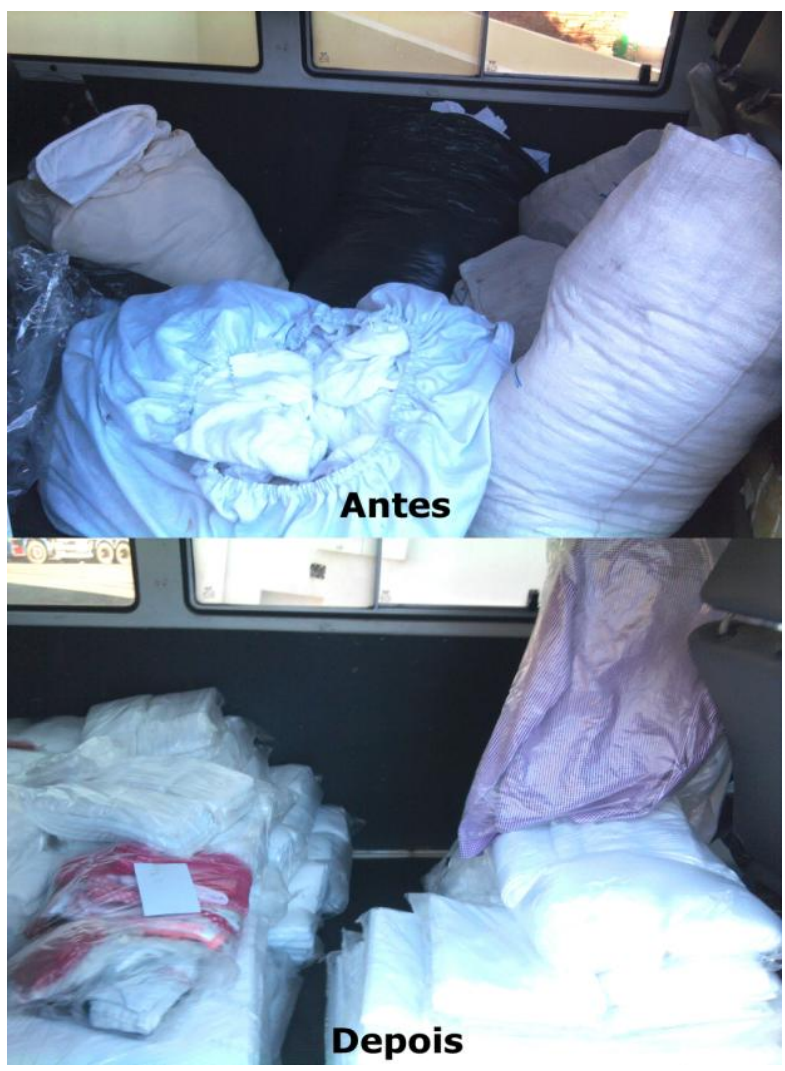

Figura 4. Melhoria na forma de entrega dos produtos.

Fonte: Autoria própria

A etapa 4 de implantação dos sensos: Os sensos de descarte e organização foram concluídos primeiramente e os sensos de limpeza, higiene/saúde e disciplina foram implantados a medida que cada senso da sequência fosse finalizado. Logo após a realização do senso de descarte: Houve melhorias como a liberação de espaço e organização do setor de recebimento, dobra e acondicionamento em Bags (bolsas para acondicionamento das toalhas prontas) para envio aos clientes.

A tabela 2 mostra a porcentagem atingida em cada processo nas avaliações dos sensos de descarte e organização. 
Tabela 2. Avaliação dos sensos de descarte e organização

\begin{tabular}{|l|c|c|c|c|}
\hline \multicolumn{4}{|c|}{ Pontuação do Senso de Descarte } & Pontuação do Senso de Organização \\
\hline Setor/mês & Agosto & Setembro & Outubro & Novembro \\
\hline Recebimento de toalhas & $50 \%$ & $70 \%$ & $70 \%$ & $90 \%$ \\
\hline Separação & $60 \%$ & $80 \%$ & $90 \%$ & $90 \%$ \\
\hline Lavagem & $30 \%$ & $50 \%$ & $80 \%$ & $70 \%$ \\
\hline Secagem & $30 \%$ & $70 \%$ & $80 \%$ & $70 \%$ \\
\hline Dobra & $30 \%$ & $80 \%$ & $100 \%$ & $90 \%$ \\
\hline Selagem & $40 \%$ & $70 \%$ & $90 \%$ & $80 \%$ \\
\hline Acondicionamento & $50 \%$ & $80 \%$ & $90 \%$ & $90 \%$ \\
\hline
\end{tabular}

Fonte: Autoria própria

A tabela 2 expõe as quantidades percentuais do senso de descarte e organização de cada setor produtivo antes e depois da aplicação do 5S. Agosto ainda foi um mês de práticas primitivas da lavanderia, e nos meses seguintes houve a implantação da ferramenta, onde foram obtidos números expressivos com a reorganização do ambiente (Novembro), descartes de materiais sem uso e armazenagem dos que serão necessários em outra etapa (Setembro e Outubro).

Através de orientações e do treinamento realizado, os próprios funcionários colocaram em prática o 5S.Com o principal objetivo de organizar os setores, evitar desperdícios, melhorar relacionamentos e facilitar a localização de recursos disponíveis.

A partir da implantação do $5 S$ a implantação do POP se torna puramente focada nas operações e as falhas foram mais passíveis de correção, pode-se trabalhar com o ciclo PDCA desde a etapa de estruturação e planejamento do $5 \mathrm{~S}$ bem como a implantação do POP, com objetivo de controlar a implantação da padronização e garantir a melhoria contínua. Esse processo de melhoria está cada vez mais evidente no mercado atual, com as empresa buscando tornar-se competitiva e atingir a excelência em qualidade.

Com a Tabela 3 e o Gráfico 1 é possível observar o avanço da empresa com a implantação das ferramentas citadas anteriormente.

Tabela 3. Levantamento de problemas

\begin{tabular}{|l|r|}
\hline Problemas & Frequência antes do POP (\%) \\
\hline Produtividade & 42 \\
\hline Avarias & 26 \\
\hline Retrabalhos & 44 \\
\hline Atrasos na entrega & 39 \\
\hline Erros no processo & 54 \\
\hline Aproveitamento do espaço & 68 \\
\hline Versatilidade dos funcionários & 25 \\
\hline & \\
\hline Problemas & Frequência depois do POP (\%) \\
\hline Produtividade & 83 \\
\hline Avarias & 13 \\
\hline Retrabalhos & 9 \\
\hline Atrasos na entrega & 11 \\
\hline Erros no processo & 21 \\
\hline Aproveitamento do espaço & 74 \\
\hline Versatilidade dos funcionários & 75 \\
\hline
\end{tabular}

Fonte: Autoria própria 


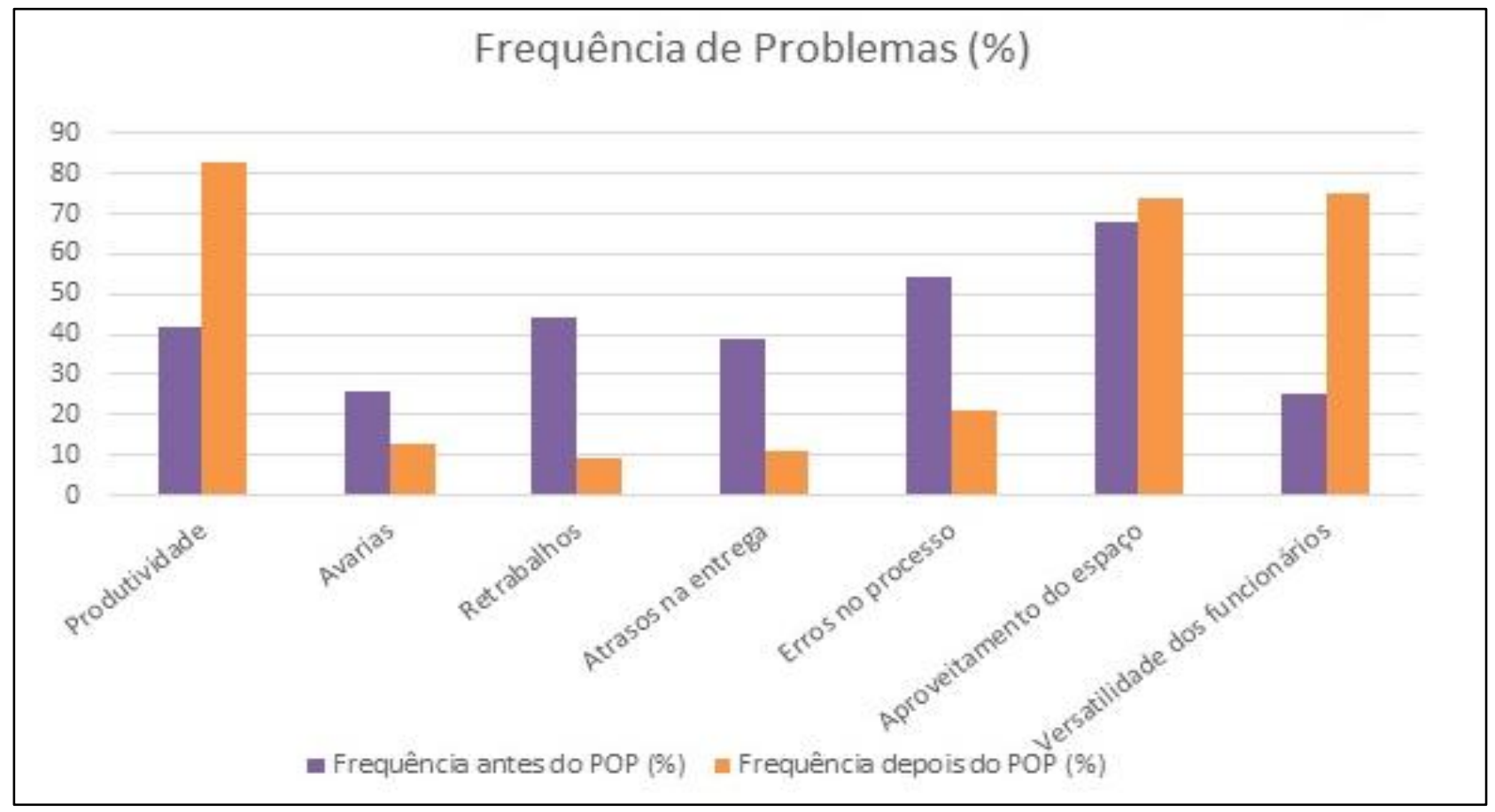

Gráfico 1. Frequência de problemas na empresa

Fonte: Autoria própria

Com a implantação do POP e as demais ferramentas na lavanderia, conseguiu-se otimizar todos os processos presentes no setor produtivo, desde 0 recebimento do produto até a entrega do mesmo aos clientes.

\section{DISCUSSÕES}

É notório, pela observação do Gráfico 1, que a implantação do POP proporcionou uma melhora significativa no desempenho devido a diminuição da frequência dos problemas ocorridos dentro da empresa. Os principais índices que obtiveram resultado favoráveis foram o aumento de produtividade de $42 \%$ para $83 \%$, e a queda no índice de retrabalho de $44 \%$ para $9 \%$, pois todo retrabalho seja na lavagem, secagem ou dobragem geram perda de tempo, diminuição da velocidade, atrasos nas entregas, hora extra e com o desfecho o aumento do custo do processo, assim, se faz necessário a busca por ações que venham a diminuir ou mesmo eliminar a ocorrências de falhas. Essa mudança no percentual é resultado da padronização dos processos, que dificultam a ocorrência de falhas, e aumentam a produtividade e, esta busca pela padronização inicia-se com a implantação de ferramentas e programas básicos e muito importantes como 5S, POP e que culminarão em uma ambiente preparado para inserção do ciclo PDCA e SDCA, após conseguir planejar, executar, checar e agir sobre os 
problemas; a fase sequencial será a padronização onde será aplicado o ciclo SDCA que visa a padronização (S de Standartization) e as demais etapas são idênticas ao PDCA.

É importante ressaltar que os POP's deverão ter monitoramento e revisões constantes, sempre culminando em melhorias, e qualquer alteração deverá ser solicitada ao responsável pelo setor.

Em reunião, a equipe deverá verificar se a alteração proposta é realmente pertinente, em caso de dúvida o líder deverá solicitar o apoio da gerência. Dessa maneira, será possível a revisão dos procedimentos comuns e os membros da equipe poderão organizar o seu trabalho, reconhecer o trabalho do outro e os pontos de conexão entre as tarefas.

A responsabilidade pela confecção dos POP's, manutenção das pastas, treinamento da equipe e verificação do cumprimento da rotina estabelecida será atribuída ao líder de produção, que disponibilizará em pasta específica todos os POP's com livre acesso a todos os colaboradores. A equipe de auditoria montada deverá auditar periodicamente e verificar a manutenção das pastas e operações dos POP's, como por exemplo, manter uma cópia em formato eletrônico.

Em relação ao $5 S$, como visto neste trabalho, é a base fundamental para a conscientização e a implantação dos demais programas de qualidade. Pois se trata de um processo educacional necessário, a ser aplicado conjuntamente com programas mais complexos, que necessitam de um ambiente organizacional de qualidade.

Ainda, deve-se destacar que o conceito de qualidade deve estar incorporado na filosofia da empresa e na vontade dos colaboradores.

\section{CONCLUSÃO}

Com a implantação de um modelo de padronização das etapas do processo de produção de uma lavanderia industrial, através da elaboração de Programas Operacionais Padronizados (POP's) com auxílio dos programas $5 \mathrm{~S}$ e PDCA, pode-se perceber a importância da sistematização e padronização dentro de uma empresa.

Estas aplicações proporcionam melhorias a qualquer tipo de empresa, dentre elas: um ambiente saudável e seguro para os colaboradores, redução de custo, qualidade no serviço prestado, aumento da lucratividade e satisfação dos clientes.

\section{REFERÊNCIAS}

AGÊNCIA ESTADO. Lavanderias preveem crescimento de $8 \%$ ao ano até 2016 . Revista PE\&GN, São Paulo, jun. 2011. Disponível em: <http://revistapegn.globo.com/Revista/Com mon/0,,EMI237090-17180,00LAVANDERIAS+PREVEEM+CRESCIMENTO+DE 
+AO+ANO+ATE.html >. Acesso em: 06 jun. 2014.

CAMPOS, V. F. Gerenciamento pelas Diretrizes. Belo Horizonte: Fundação

Christiano Ottoni, Escola de Engenharia da Universidade Federal de Minas Gerais, 1996.

CANTO, L. C. C.; SANTOS, L. C. \& GOHR, C. F. Implantação do sistema $5 S$ no setor de armazenamento de uma empresa de pequeno porte do sul de Santa Catarina. XXVI ENEGEP in Anais...ABEPRO, Fortaleza, $2006 . \quad$ Disponível em: <http://www.abepro.org.br/biblioteca/ENEG EP2006_TR470319_7396.pdf>. Acesso em 08 ago. 2014.

DEMING, W. E. Qualidade: a revolução da administração. Rio de Janeiro: MarquesSaraiva, 1990.

FONSECA, A. P., et al. Sistema de Gestão pela Qualidade Total e Padronização na Empresa. Disponível em: <http://www.unisalesiano.edu.br/encontro2 007/trabalho/aceitos/CC21778734871.pdf>. Acesso em: 10 jul. 2014.

GUIMARÃES, M. Proposta para implantação de gerenciamento de processos e da rotina em uma empresa de pequeno porte.2011. Trabalho de Conclusão de Curso (Bacharel em Engenharia de Produção). Faculdade de Engenharia, Universidade do Estado de Santa Catarina, Joinville.

LIN, C. C.; LUH, D. B.A vision-oriented approach for innovative product design.AdvancedEngineeringInformatics, v. 23, n. 2, p. 191-200, 2009. http://dx.doi.org/10.1016/j.aei.2008.10.005

MARSHALL, I. et al. Gestão da Qualidade.8a ed. Rio de Janeiro:Editora FGV, 2006.

NEVES, T. F. Importância da Utilização do Ciclo PDCA para Garantia da Qualidade do Produto em uma Indústria Automobilística.
2007. 56 f. Trabalho de Conclusão de Curso (bacharel em Engenharia de Produção) Faculdade de Engenharia, Universidade Federal de Juiz de Fora, Juiz de Fora.

PINEZE, E.C; CONSONI, R.C; MARQUES L.C. Procedimentos Operacionais de uma indústria farmacêutica: proposta de critérios de elaboração. Disponível em: <http://fitoscience.com.br/administracao/upl oad/20100709_123139.pdf>. Acesso em 30 maio 2014.

SINDLAV. Certificação para Lavanderias.Cartilha informativa. Disponível em: $\quad$ http://www.sindilav.com.br/SQS/>. Acesso em: 22 maio 2014.

STAINO, M. M. L. et al. Implantação da gestão por processos em uma pequena empresa de base tecnológica: diferencial de competitividade. Revista Eletrônica Produção \& Engenharia, Viçosa, v. 4, n. 2, jan./jun., 2013. Disponível em:

$<$ http://www.revistaproducaoengenharia.org /arearestrita/arquivos_internos/artigos/21305\%20-\%20formatado\%20em\%206-813.pdf>. Acesso em: 09 ago. 2014.

YIN, R. K. Estudo de caso: planejamento e métodos. 2. ed. Porto Alegre: Bookman, 2001 